\title{
EL TÚ DEL PRESIDENTE. LA RUPTURA DEL ROL SOCIAL*
}

\author{
JAVIER MEDina López \\ Instituto Universitario de Lingüistica «Andrés Bello» \\ Universidad de La Laguna
}

\begin{abstract}
RESUMEN
El programa de la televisión española «Tengo una pregunta para usted» emitió el 27 de marzo de 2007 una entrevista al presidente del Gobierno español. En la misma, un colectivo de cien personas tenía la posibilidad de hacer alguna pregunta al invitado esa noche a lo largo de las dos horas que duró el programa. El mismo fue todo un éxito de audiencia. La respuesta periodística y social fue extraordinaria. Se trataba de un formato televisivo novedoso en España. En este artículo su autor analiza el contexto sociopragmático de la entrevista presidencial, prestando especial atención al rol social desempeñado por el presidente así como parte de su comportamiento lingüístico. En efecto, en el terreno de las formas de tratamiento, el presidente recibió un cortés usted, mientras que éste decidió -contra todo pronósticoemplear un tú dirigido a todos sus interlocutores que resultó, si atendemos a las numerosas críticas periodísticas, un auténtico acto de descortesía social. En el marco de la cortesía, además, se tratará de enmarcar la interacción presidencial.
\end{abstract}

Palabras clave: cortesía, actos de habla, formas de trato, lengua española.

\section{ABSTRACT}

During the emission of the TV program called «Tengo una pregunta para usted», broadcasted by the Spanish National TV (TVE1) on march 27th, the public could pose a question to the prime minister of the Spanish Goverment. During the interview, one hundred persons had the possibility to realise a question to the guest, during the two hours. The reaction of the press and general public was extraordinary. The TV format was a novelty in Spanish TV. In this article the author analyzes the sociopragmatic context of the prime minister interview, paying special attention to the «social role» played by the premier. The forms of address used by the President is the focus of our linguistic research. The premier was addressed using the polite form usted but he decided to use the tú form in all his answers.

Key Words: politeness, speech act, address forms, Spanish language.

* Agradezco enormemente la lectura crítica de este trabajo y las sugerencias de mejora hechas por los siguientes colegas: Dra. Susana Boretti (Universidad Nacional de Rosario, Argentina), Dra. Nieves Hernández Flores (Escuela Superior de Comercio de Copenhague, Dinamarca) y Dr. Manuel Almeida (Universidad de La Laguna, España). Sobra decir que todo lo erróneo que pudiera haber en estas páginas incumbe sólo a mi criterio. 


\section{INTRODUCGIÓN}

El día veintisiete de marzo de 2007 la televisión pública española a través de su primer canal (TVE1) y Radio Nacional de España (RNE) emitieron simultáneamente un programa novedoso a las 21:30 horas ${ }^{1}$ que tuvo un gran éxito de audiencia directa ${ }^{2}$ la noche de su salida en antena y que ocasionó, por algunos hechos que más adelante analizaré, una enorme repercusión social, periodística, política y, lo que a mí ahora más me interesa, sociopragmática. El formato de dicho programa-cuyo título es Tengo una pregunta para usted- se basa en la adaptación de uno similar (de carácter popular, que busca frescura y cercanía del político a la gente) ofrecido por la televisión francesa $\mathrm{TF} 1$ (J'ai une question à vous poser) en el que se entrevistaba a los políticos Nicolas Sarkozy y Ségolène Royal, aunque adaptándolo a los gustos e intereses de los profesionales de TVE1 en España. El invitado especial de este original programa televisivo fue el presidente del Gobierno español, el socialista D. José Luis Rodríguez Zapatero.

En un plató de 360 grados un colectivo de cien personas podía hacer una pregunta al presidente en directo, sin que mediara un filtro previo o un guión preestablecido, salvo los aspectos técnicos que, naturalmente, siempre concurren en una situación de estas características ${ }^{3}$. La realidad fue que, por cuestión de tiempo ${ }^{4}$, no todos los seleccionados pudieron realizar una pregunta, pero una parte importante de los mismos sí pudo interrogar al presidente sobre diferentes temas de interés para el país en ese momento: terrorismo, seguridad, inmigración, paro, política interna, comercio, vivienda, salud pública, problemas del mundo rural, etcétera.

\section{EL TÚ DEL PRESIDENTE}

\subsection{Objetivos del trabajo}

En este trabajo me propongo analizar, dentro del contexto de la cortesía lingüística y social, el tuteo que el presidente del Gobierno espa-

${ }^{1}$ Una hora menos en Canarias. El programa se pudo ver también por el Canal 24 horas, Canal Internacional de TVE y <www.rtve.es $>$.

${ }^{2}$ Según fuentes periodísticas, el 30,3\% de share, que se traduce en unos 5.834.000 espectadores, siendo el «minuto de oro» a las 22:41 de la noche, lo que supuso en ese momento un total de 7.261.000 personas (34.5\% de cuota de pantalla) que sintonizaban TVE1. Información de <http://www.elpais.com>. Los datos de los audímetros muestran que más de 16 millones de personas conectaron, en algún momento, con Tengo una pregunta para usted.

${ }^{3}$ Como, por ejemplo, el ensayo general hecho la misma mañana del día de la emisión para ajustar aspectos técnicos y escenográficos, sin la presencia, naturalmente, del presidente.

${ }^{4} \mathrm{Al}$ final sólo 22 hombres y 17 mujeres pudieron intervenir, lo cual supuso que formularan 42 preguntas. Información de «Sala de Prensa», en <http://www.rtve.es $>$ y en esta misma página el resumen de la noticia que da la agencia EFE fechado el 27 de marzo de 2007. 
ñol utilizó en el programa televisivo de referencia, las consecuencias que el mismo ha tenido en el sector de la prensa española y dar una explicación en el marco de la sociopragmática a este comportamiento lingüístico. Me interesa, llegado a este punto, poner de relieve el concepto de imagen. La imagen presidencial, en realidad la imagen básica del presidente $^{5}$, fue censurada grosso modo desde diferentes perspectivas e intereses ideológicos, políticos y también fue vista como un acto de «descortesía», al atentar él mismo contra la propia imagen socialmente aceptada que se tiene de un presidente en el contexto sociocultural español. Muestra palpable de esto que digo es el conjunto de opiniones que se refiere al tú de Rodríguez Zapatero. En efecto, si se analiza la prensa escrita publicada días después de la emisión de Tengo una pregunta para usted y se tienen en cuenta los habituales puntos de vista de periodistas, políticos, politólogos y público en general en las numerosas tertulias radiofónicas y televisivas, se observará que dos hechos particulares fueron los que más significativamente llamaron la atención:

a) La respuesta dada por el jefe del Gobierno español ante la pregunta de si sabía cuánto valía un café, a la que respondió que 80 céntimos. Sin duda una «aparentemente intranscendente pregunta» y una «ingenua respuesta» que han atraído la atención de numerosos comentaristas que se resume en un sentimiento: el presidente no está al cabo de lo que «en realidad» cuesta el precio de un café en España. Por lo tanto, según esta percepción, el poder aleja de la realidad. Es obvio que el análisis no sólo se circunscribe a esta anécdota, máxime si se tiene en cuenta, además, que en otros muchos lugares de España que no sean Madrid el café, en efecto, ronda ese precio. Otros comentarios y análisis abordaron los asuntos de más calado político.

b) El tuteo generalizado que el presidente empleó, frente al usted que recibió siempre por parte del público y presentador del programa al que -en un gesto de proximidad- llamaba por su nombre propio. La aparición de las dos formas pronominales habituales de segunda persona del singular en España (tú / usted) y su uso asimétrico en direcciones opuestas es lo que ha producido una general desaprobación.

Será de este último punto del que me ocuparé en las páginas que siguen. El análisis político, como es obvio, no me corresponde a mí hacerlo, ni en estos momentos ni en este estudio.

\footnotetext{
5 Véase más adelante el apartado 2.2.1. para el concepto de «imagen básica» propuesto por Bravo 2004.
} 


\subsection{La muestra de la sociedad española}

La idea de que una persona desconocida tuviera acceso al presidente del Gobierno de España en un programa en directo era el objetivo que se plantearon los programadores de TVE1 y, además, desde el punto de vista político-ideológico, venía a mostrar los nuevos tiempos de apertura y cercanía del poder hacia sus gobernados. El mismo Rodríguez Zapatero se refería a su propia actuación en televisión delante de un grupo de periodistas en la cafetería interna del Congreso de los Diputados con los siguientes términos:

Esto es buenísimo para la democracia. Ya no tiene marcha atrás. Fue algo que tuvo novedad y autenticidad. Es una pequeña revolución. Y se le ha ocurrido a la televisión pública, pero si lo hubiera hecho una privada también habría sido [El Mundo, 29-03-2007, p. 20].

La empresa (Instituto) TNSDEMOSCOPIA (Grupo Sofres), habitual en los sondeos y muestreos políticos en España, seleccionó según una serie de parámetros sociológicos la muestra de cien personas que, de alguna manera, representaba a la actual heterogénea sociedad española. Se llevó a cabo una «selección cualitativa», lo que supone buscar el perfil del ciudadano que se adapte a las variables consideradas para el diseño de la muestra. Así, cinco grandes variables fueron las que configuraron la cala sociológica de este experimento televisivo:

1. Comunidades Autónomas: todas estuvieron representadas, incluyendo las ciudades de Ceuta y Melilla. Al final tuvieron la oportunidad de intervenir haciendo preguntas 4 madrileños, 3 catalanes, 3 andaluces, 3 de la Comunidad valenciana, 3 de Galicia, 2 de Castilla y León, 3 del País Vasco, 2 de Aragón, 1 de Asturias, Castilla-La Mancha y Canarias, 2 de las Islas Baleares, Murcia y Navarra, 1 de Cantabria, La Rioja, Extremadura y Melilla.

2. Sexo: esta variable tendrá en cuenta la paridad social, promovida en buena medida por el Gobierno socialista. La muestra tuvo en el plató de TVE1 51 hombres y 49 mujeres.

3. Edad: la distribución se hizo teniendo en cuenta cuatro franjas de edad. Es decir, entre los 18 y los 31 años (25 personas); entre los 32 y 44 (26 personas); entre 45 y 60 (24 personas) y más de 60 años (25 personas).

4. Afinidad política: ésta se refiere a la representación política que tiene la muestra en el momento en que se realizó el programa y está basada en la configuración del Congreso de los Diputados español, que es el resultado de las últimas Elecciones generales celebradas en marzo del año 2004. Por partidos la muestra queda como sigue: 40 sujetos se sienten más afines al PSOE; 35 al PP; 
6 a IU, ICV/EU; 4 CIU; 3 a Ezquerra Republicana de Catalunya; 2 con el Partido Nacionalista Vasco, Coalición Canaria, Bloque Nacionalista Gallego y Unión del Pueblo Navarro; 1 con la Chunta Aragonesista, Eusko Alkartasuna, Nafarroa Bai y Abstencionistas militantes.

5. Perfil laboral: de los cien sujetos seleccionados, 62 trabajan en el momento de la entrevista; 14 están jubilados o prejubilados; 10 son estudiantes; 9 son amas de casa y 5 se encontraban en paro en aquel momento. El abanico laboral es muy amplio: abogado, agricultor, administrativo, pescador, músico, peluquera, criminólogo, director ejecutivo, enfermera, dentista, cocinera, jefe de estudios, mecánico, técnico electricista, vendedor de cupones, etcétera.

Como puede observarse, la muestra televisiva representa a los variados sectores que componen la sociedad española. Aunque para mis propósitos la representatividad de aquella no es un elemento clave (dado que sus conclusiones no dependerán de si el muestreo está bien hecho o no, por ejemplo), sí considero interesante, no obstante, dar a conocer estos datos para situar el comportamiento y actitud lingüísticos de las dos partes que intervinieron en la interacción-entrevista. Por un lado, la del público presente que empleó usted (además del honorífico Sr. Presidente) y, por otro, la del presidente del Gobierno que utilizó tú. Para mis objetivos será la actitud dialógica de este último la que más me interese.

\subsection{Algunas repercusiones periodísticas de la entrevista. Puesta en escena y tuteo}

Al margen del análisis político que una entrevista de esta envergadura conlleva, sí quisiera mostrar algunos aspectos que la prensa española publicó a los pocos días de celebrarse el programa televisivo y que, en cierto modo, me ayudan a contextualizar la intervención lingüística del presidente. Como no podía ser de otra forma, un programa novedoso de estas características ha despertado la curiosidad de los especialistas en imagen y comunicación desde varios ángulos. Uno de ellos es el que se refiere, por ejemplo, a la puesta en escena del «actor = participante» esa noche. Por ello, en el caso de Rodríguez Zapatero, se han analizado sus gestos, el contenido del mensaje o el atuendo.

Más interesantes resultan, para mis propósitos ahora, los comentarios hechos en la prensa española en la que se destaca el uso ¿descortés? del presidente al emplear, casi en su totalidad, el pronombre de segunda persona tú en lugar del protocolario usted, máxime tratándose 
de un programa de televisión. La relación desigual en el trato, así pues, estaba dada. Proporciono las citas más ilustrativas de El País, El Mundo, ABC y La Razón:

Escasa naturalidad, a pesar de recurrir al tuteo como gesto de acercamiento. [El País, 29-03-2007, p. 14].

Sorprendió también la decisión del presidente del Gobierno de tutear a todos sus interlocutores, al margen de su edad y pese a que todos ellos le trataron de usted. El tuteo no sirvió para acortar distancias, sino que marcó las diferencias entre el presidente del Gobierno y el resto de los ciudadanos. Todos estos detalles contribuyeron a alejar al protagonista y a hacer más difícil la identificación con él, lo que suele ser el objetivo político en este tipo de programas. [El País, 29-03-2007, p. 24].

De hecho, el presidente se esforzó por mostrarse muy próximo a sus entrevistadores y llamó de tú a todo el mundo. [El Mundo, 29-03-2007, p. 22].

El problema ocurre [...] cuando presumen de talante común y tutean al interlocutor pero se saltan las colas o mandan abrir paso a los guardias en medio de un atasco. [ABC, 29-03-2007, p. 5].

José Luis Rodríguez Zapatero se apareció en carne mortal al centenar de ciudadanos seleccionados para el caso y, todos envueltos en un decorado chafarrinón, les habló de tú. Los poderosos que hablan de tú y escuchan usted son siempre sospechosos y acreditan la falta del sentido de simetría que tanto define el sentimiento hondo del desprecio a los demás. Se trataba de «innovar» la entrevista en televisión. [ABC, 29-03-2007, p. 6].

Sobre el tuteo argumentó que le cuesta el trato «de usted». [ABC, 29-03-2007, p. 24].

Afrancesado, salvo en el recurso al tuteo a los entrevistadores. [ABC, 29-032007, p. 25].

En lugar de «querida amiga», Zapatero respondía con el tuteo real (royal). Sin embargo, Ségolène contestaba con un «monsieur» 0 «madame» a sus contrarios, igual que Sarkozy, incluso con los jovenzuelos más redichos. Al presidente sólo se le escapó un usted con el del café ( «respeto su circunstancia personal»). [ABC, 29-03-2007, p. 25].

A Rajoy no lo tuteó como a los 100 ciudadanos que participaron en el programa de la noche del martes y tampoco le dijo que compartieran su preocupación por el asunto, mucho menos que tomaba nota para buscar soluciones al respecto. Nada de eso. [La Razón, 29-03-2007, pág. 15].

Pero indudablemente, y como no podía ser de otra forma teniendo en cuenta la cada vez más creciente, necesaria y comunicativa red de redes que supone Internet, pueden hallarse comentarios, críticas y fo- 
ros en infinidad de páginas en las que se opina sobre lo acontecido con dicha entrevista televisiva y el tuteo generalizado del presidente. Sólo como muestra de la búsqueda que he realizado traigo a colación algunos ejemplos:

Al principio sonó excesivamente coloquial el tuteo de Zapatero, con Lorenzo Milá nada más entrar y luego con el resto. Me imagino que en un hombro tenía a su director de comunicación diciéndole que tuteara, y en el otro al ángel de la guarda diciéndole, como es lógico, que es el presidente del Gobierno y que si se tratan de usted, hay que responder de usted, o de tú diciéndole «no me trate de usted». Esos detalles molan. Al final se lió un poco con eso, pero tiene mérito estar ahí ante 100 paisanos, en directo y en la tele. [http://www.blogdeladversario.blogspot.com, 30-03-2007].

En su comparecencia televisiva ante el pueblo, Rodríguez Zapatero se dirigió a él de tú. El pueblo, como es natural, le hablaba de usted. Rodríguez Zapatero, no. Él se empeñó en tutear a sus interlocutores. ¿Mala educación? Peor que eso: pésima. [...] Además, Rodríguez Zapatero estaba trazando una línea. Fuera de la familiaridad que traza el tuteo [...]. [http://www.libertaddigital.com, 24-04-2007].

Uno de los detalles que más se criticó del presidente es que se dirigiera a los ciudadanos llamándoles de tú, cuando, según los expertos, es una fórmula que no debe utilizarse nunca por «respeto» a los interlocutores. Como se sabe, el único que puede permitirse el lujo de tutear a la gente en público es el Rey. Zapatero justificó su campechanía argumentando que «no le sale» llamar de usted a la gente [...] [http://www.diariocritico.com, 24-04-2007].

Lo más llamativo, con todo, de la entrevista múltiple a Zapatero en TVE fue que mientras los asistentes le hablaban de usted, él tuteaba a todo el mundo. Se trata de un estilo personal, sin duda, de una actitud no premeditada, seguro, pero que confería al presidente un indeseado tono paternalista, de superioridad, que desvanecía la presunta horizontalidad del encuentro [...] En las entrevistas informativas, el tuteo suena inevitablemente a compadreo, a acuerdo previo entre entrevistador y entrevistado y, por eso, lo proscriben todos los libros de estilo periodísticos, que, como todo el mundo sabe, son los textos más incumplidos junto con el Código de la circulación [...] Por mi parte, seguiré reservando el tuteo para la intimidad y desearía que nuestros políticos hicieran lo mismo cuando su relación no sea la de un partido de fulbito, sino la equilibrada y recíproca que debe existir entre administrador y administrado. [http://www.diariocritico.com, 24-04-2007].

Pero comienza a asomar la cabeza otra crítica a la actitud del presidente del Gobierno en Tengo una pregunta para usted: el tuteo con el que ZP respondía al «usted» de sus interlocutores, algo que el protocolo sólo reserva al Rey de España. [...] Zapatero tuteaba al presentador y a los entrevistadores. Les llamaba por el nombre de pila, como si fueran «colegas» [...] «Señor Presidente: los republicanos hablan de usted», le dijo Del Pozo. «Lo hice por cercanía. El usted me sale más forzado. Eso de usted es más bien una cortesía francesa [...]» [http://www.elsemanaldigital.com, 24-04-2007]. 
Hace unos días, en Tengo una pregunta para usted (TVE), el presidente Rodríguez Zapatero utilizó el tuteo para dirigirse a los ciudadanos reconvertidos en interrogadores. El martes, en Antena 3, y por coherencia, también recurrió al tuteo para dialogar con Gloria Lomana, Alfredo Urdaci y Juan Pedro Valentín. Se trata de un tuteo paranormal, distinto al que se practica en Los Serrano (Tele 5), ya que, en lugar de acercar, distancia, probablemente porque el estilo disgresivo de Zapatero contiene un mecanismo de dispersión letal para sus interlocutores: por más que intentes concentrarte en sus explicaciones, acabas perdiendo el hilo. [http://www.vertele.com/criticas, 24-04-2007].

Una variadísima gama de opiniones de toda índole está a disposición de quien quiera cotejarlas en Internet a través de los foros que tanto abundan en la red y en los que, en la mayoría de las ocasiones bajo seudónimos o nicks, los participantes expresan libremente sus puntos de vista sobre asuntos de actualidad o de gran impacto informativo, como es el caso que nos ocupa. Las heterogéneas cuestiones aquí planteadas dejan entrever, desde otra perspectiva social, un bosquejo de la conciencia lingüística que tienen los hablantes, cuáles son sus creencias y actitudes (negativas y positivas), por ejemplo, ante el tratamiento y ante las consecuencias de una ruptura que, como la producida por el presidente, ocasiona la alternativa del tú o del usted. En los ejemplos que a continuación muestro pueden atisbarse algunas de las cuestiones sobre las que aquí llamo la atención:

Ayer en la serie de preguntas que han hecho a nuestro Presidente, el Sr. Zapatero, trató a todos de tú. Pues, no. No creo que se deba de hacer. Dicen los entendidos que es para estar más cerca de las personas. ¡Oiga!, para estar más cerca del pueblo hay que cumplir con las promesas electorales, con todas [...] Pero a lo que iba: Sr. Presidente, por favor, use el usted, queda mejor... es mi opinión. [http://mas.1ne.es/foros, 24-04-2007].

Ya, pero la imagen «buen rollito» queda mejor el tú. [http://mas.1ne.es/foros, 24-04-2007].

El tratamiento de tú en el caso que nos ocupa, creo que responde a una táctica estudiada pero, a mi entender, equivocada. Si yo estuviese allí, entre la plebe, me sentiría muy molesto. Sentiría estar tratando con una persona maleducada. Posiblemente yo me dirigiera a él con el mismo tratamiento y seguro que la cosa quedaría mal. [http://mas.1ne.es/foros, 24-04-2007].

Puede usted tratarme de tú, pero con educación por medio. Siempre que exista una educación en cualquier persona, el tratamiento de usted y de tú ha de ser de común acuerdo. Pero lo importante es la educación.

[http://mas.1ne.es/foros, 24-04-2007].

Lo que no es «educado», bajo mi criterio, es la imposición, tanto del «tú» como del «usted». [http://mas.1ne.es/foros, 24-04-2007]. 
Hay veces que cuando usted se dirige a mi persona, no sé si es falta de educación (en algunas ocasiones) o con una cierta ironía. Estaré al tanto para distinguir posibles «anomalías». [http://mas.1ne.es/foros, 24-04-2007].

No se te escape considerar también sus intervenciones... aunque las presentes con el «envoltorio» del «usted». [http://mas.1ne.es/foros, 24-04-2007].

Los comentarios y análisis llevados a cabo por buena parte de la prensa escrita española de tirada nacional que es, como se ha visto, la que aquí recojo sólo como ejemplo de las repercusiones de la actuación presidencial, ponen de manifiesto dos hechos significativos bajo mi punto de vista. Por un lado la «anécdota del café», que por ser tal no entraré en consideraciones particulares y, por otro, el comentado «tuteo presidencial». En este segundo caso observo una generalizada crítica -incisiva o complaciente en función del que escribe y de la empresa periodística- en la que no se percibió como un acto social adecuado, correcto y adaptado a las circunstancias el hecho de que el presidente del Gobierno de un estado democrático tuteara a sus interlocutores, al margen del usted recibido, de la clase social, del nivel de instrucción, del sexo de los interlocutores y del contexto comunicativo (muy formal). La vulneración de estas reglas conversacionales y de la cortesía dio lugar -si atendemos al corpus aquí compilado- a todo un conjunto de implicaturas conversacionales cuya interpretación ha quedado en manos de la audiencia y su posterior reacción. El uso de usted por un lado y el de $t u ́$ por otro pueden ser «concebidos como significaciones implicadas respecto a las máximas de cortesía que el hablante postula en determinados contextos» según Blas Arroyo 1994, p. 15. De manera consciente por parte del Sr. Rodríguez Zapatero -siguiendo el esquema clásico de las díadas propuestas por Brown y Gilman 1960- este se propuso una ruptura del esquema simétrico (que hubiera supuesto el empleo del usted en las dos direcciones $)^{6}$ a favor del uso asimétrico por parte de uno de los participantes en esta modalidad de entrevista (usted del público y tú del presidente). Blas Arroyo 1994, p. 14 -quien realiza un exhaustivo repaso a toda la teoría de la cortesía relacionada con las formas de trato en los trabajos ya clásicos de Lakoff 1973, Leech 1983 y Brown y Levinson 1987, entre otros ${ }^{7}$ - hace notar cómo en los intercambios asimétricos (tú-usted), cuya interpretación está basada en los factores ya arriba señalados (sexo, edad, diferencias de poder, etc.), «el interlocutor situado en la posición jerárquicamente inferior se ve impelido a cumplir con la primera máxima de cortesía y mostrar su respeto hacia el hablante superior, lo que se traduce en un uso socialmente normati-

${ }^{6}$ La otra posibilidad simétrica hubiera sido un tú recíproco (público y presidente) nada esperable, según mi criterio, en este contexto.

7 Cf. más adelante el apartado 2.4 . 
vo del usted». En el caso que nos ocupa se añade el hecho de estar en un programa televisivo y en una entrevista al presidente del Gobierno.

Pero el tema del tuteo del Sr. Rodríguez Zapatero parece ser un asunto que ha llamado la atención en más de una ocasión, si tenemos en cuenta la cantidad de información que aparece en la prensa y en Internet sobre este asunto y que se justifica, obviamente, por tratarse de un personaje público de alta relevancia social en la jerarquía política española. Sólo de forma ilustrativa indico el comentario de una noticia que contiene el periódico Libertad digital, en el que se da cuenta de una entrevista hecha también en TVE1 al presidente del Gobierno el 19 de enero de 2005 en la que se trataron diversos temas de actualidad ${ }^{8}$. Casi al final de esta información encuentro lo siguiente:

Y el presidente contestó a medias entre el tuteo y la lejana cortesía: «Le agradezco que me hagas [los subrayados son míos] estas preguntas: hay una comisión de sabios que van a producir un informe que se traducirá en una reforma legislativa». [http://www.libertaddigital.com, 30-03-2007].

\section{LAS FORMAS DE TRATAMIENTO EN LA INTERACCIÓN SOCIAL}

Parece un universal lingüístico que todas las lenguas del mundo poseen determinados mecanismos a través de los cuales se establece la modalidad de trato hacia el interlocutor, si bien es cierto que en todas no funciona de la misma manera y que estas estructuras están condicionadas -aquí más si cabe- por parámetros tanto de orden interno (lingüísticos) como de orden pragmático o social (sociolingüístico, pragmalingüístico o simplemente, para algunos, extralingüístico). El tratamiento es un sistema de significación a través del cual unas personas se relacionan con otras. En muchos casos, podemos hablar de una actividad ceremonial o protocolaria, en otros, como sabemos, la ruptura de sus límites puede llegar a la jurisdicción del Código Penal (insultos, injurias, calumnias...).

Quizá sean las formas de trato dentro de los estudios lingüísticos las que ofrezcan una mayor proyección hacia el enfoque sociolingüístico, pues aunque éstas se presentan bien definidas desde el punto de vista gramatical, no lo están tanto desde la perspectiva del uso, donde se observa que el empleo de una u otra forma depende no sólo de las características individuales de los hablantes (edad, sexo, nivel cultural, jerarquía o casta) y de los aspectos psicolingüísticos que en cada uno de ellos opera (grado de confianza, cercanía, respeto, familiaridad...), sino sobre todo -y este es un aspecto cada vez más puesto de relieve en las

\footnotetext{
${ }^{8}$ Los periodistas fueron Javier González Ferrari, presidente de Onda Cero, Nativel Preciados, Charo Zarzalejos y José Antich, director de La Vanguardia. El moderador fue Lorenzo Milá.
} 
investigaciones- por el contexto sociocomunicativo y de los rasgos de la propia comunidad de habla en la que tiene lugar la interacción. En el lenguaje coloquial, además, entra en juego de manera notable el aspecto formal e informal que va directamente unido al contexto en el que se desenvolverá el mensaje. Por el contrario, en los registros más formales prevalece de manera determinante el contexto de situación, marcado muchas veces por los actos protocolarios. Al margen de las estructuras de tipo gramatical (como se verá infra), los usuarios de una lengua también aprenden las reglas que rigen el uso de la misma, dentro de ese transvase continuo que se da entre la competencia gramatical y la competencia sociolingüística, pragmática o, en definitiva, comunicativa. Tal es lo que manifiesta Almeida 2003, p. $219^{9}$ cuando define el «contexto de situación» en los siguientes términos:

Estas reglas tienen que ver con el efecto que determinados factores provocan en la selección lingüística: el tema de conversación, el carácter formal/informal de la situación, la relación entre los interlocutores (según factores como el grado de conocimiento, la edad, el prestigio o el sexo), el lugar de encuentro (público/privado), el tipo de acción, etc. El conjunto de factores socialmente relevantes en la selección lingüística constituye el contexto de situación, mientras que el conjunto de rasgos lingüísticos adscritos a cada contexto constituye el estilo de habla o registro.

Blas Arroyo 1995a, pp. 238-239, en la misma línea, pone de manifiesto la importancia que adquiere para explicar el funcionamiento de estas formas la «variación contextual» que es, a su juicio, un aspecto que ha estado poco considerado en la investigación referida al tratamiento y que sin duda ayudaría a explicar mejor la interacción verbal.

El tratamiento se enmarca en la distancia social cuya valoración y puesta en práctica en cada lengua dependerá de las características in-

${ }^{9}$ Hace notar Almeida 2003, pp. 219ss. que la idea de «contexto de situación» fue propuesta inicialmente por Malinowski, quien la circunscribe al conjunto de aspectos concretos o circunstanciales de la interacción. Más tarde Firth trató de los universales lingüísticos que, como tales, pudieran operar en cualquier «contexto de situación»: 1) los participantes y el tipo de roles y estatus que representan; 2) la acción de los participantes, considerada en su aspecto verbal y no verbal; 3) aspectos del entorno que están determinando la acción, y 4) los efectos de la acción verbal. Sin embargo, explica Almeida 2003, p. 220 que todavía no hay un consenso a la hora de considerar cuáles son los elementos que integran el «contexto de situación», ni de cómo interpretar su funcionalidad, en buena medida por razones teóricas distintas de un estudio al otro y por la heterogeneidad (relativismo) cultural en el que se ven sometidos dichos factores. Seis son los inconvenientes que Almeida 2003, pp. 220-222 pone de relieve para el estudio del contexto de situación: 1) la dificultad en la obtención de los materiales; 2) la concepción sobre la variación estilística; 3) la relación entre contexto social y lengua; 4) la circunstancia de que la interacción no es estática, sino que se va negociando o puede negociarse entre los interlocutores; 5) hasta qué punto los aspectos culturales implícitos en una comunidad llegan a delimitar el contexto, y 6) cómo se especializan o no ciertas variantes lingüísticas en contextos de situación específicos. 
trínsecas de los participantes en la interacción. Así lo señala Escandell Vidal 2005, pp. 57-58:

La distancia social es la relación que existe entre el emisor y el destinatario, tal y como la definen las propiedades de los individuos, tanto las físicas o intrínsecas (edad, sexo, etc.) como las sociales (poder relativo, autoridad...). Es una medida de la relación entre dos interlocutores que tienen componentes objetivos y subjetivos, individuales y sociales [...] La distancia social interviene en la comunicación como parte integrante de un conjunto de representaciones ampliamente compartido por los miembros de una determinada cultura. [...] Nuestras relaciones están, pues, condicionadas por la manera en que percibimos -en que hemos aprendido a percibir- la relación con los demás.

El paradigma pronominal en la lengua española es relativamente simple desde el punto de vista gramatical. Está conformado por un esquema diádico que se reparte entre un tú general en España y zonas de América, continente donde alterna con el vos (en las llamadas zonas voseantes) como formas más cercanas y un usted panhispánico que se presenta como marcador de distancia ${ }^{10}$. En el compendio que lleva a cabo Fontanella de Weinberg 1999, pp. 1401-1406 se observan los cuatro sistemas que describe para la lengua española teniendo en cuenta los rasgos de confianza y solidaridad. Los sistemas I y II son los más utilizados en España:

a. Sistema pronominal I: tú-usted en singular y vosotros / as-ustedes en plural. Empleado en gran parte de España.

b. Sistema pronominal II: tú-usted en singular y ustedes para el plural. Usado en zonas peninsulares, Canarias y regiones de América.

La aparición de una o varias de las unidades del sistema tiene, como es bien conocido, repercusiones no sólo en el ámbito del paradigma pronominal, sino que, además, éste está influyendo en la selección de una forma verbal determinada o, en ocasiones, paradigmas que incluso llegan a mezclarse, dando lugar a modelos mixtos. Tal es lo que ocurre con las formas verbales correspondientes del voseo americano y también con la acentuación (monoptongación o no) del mismo. Sin embargo, desde la perspectiva del uso sociopragmático, este conjunto pronomi-

${ }^{10}$ Evito ahora en este punto catalogar tú/vos/usted como familiar/no familiar, cercano/cortés, solidario/distanciador, etc., habida cuenta de que en función de la perspectiva en la que nos situemos cada pronombre tiene un distinto valor. Una amplia visión sobre estos y otros aspectos puede encontrarse en Blas Arroyo 1994, 1995a y 1995b y una exhaustiva bibliografía -muy actualizada- sobre el tratamiento en Fernández 2006, al que remito para su consulta. También un estado de la cuestión puede verse en Hummel, Kluge y Vázquez Laslop 2010. 
nal -auténticos marcadores sociales y formales de la cortesía en español- contrae todo un conjunto de hechos semánticos y distribucionales que los hacen depender en gran medida de las relaciones sociales de los hablantes y del medio sociocultural en que estos se desarrollan. El modelo presentado por Fontanella 1999 y explicado por Álvarez Muro y Carrera de la Red 2006, p. 119, pone de manifiesto, según estas autoras, las carencias que presenta dicha descripción, pues no permite ver con claridad la función que cumplen dichos pronombres, toda vez que la misma está circunscrita a los tokens; es decir, hace más hincapié en las manifestaciones que en su verdadero significado sociopragmático. Entender, por tanto, los marcadores pronominales de trato desde esta última perspectiva se erige en un factor clave, toda vez que -junto con el enfrentamiento dialógico entre emisor y destinatario- se «revelan habitualmente los contextos socioeducativo y empírico, a través sobre todo de los tratamientos (¿por qué trato siempre a mi padre de tú y a mi suegro de usted?) y de la cortesía (¿por qué digo habitualmente «gracias» a mis amigos y no a mi marido?)»(Vigara Tauste 1992, p. 356). Por todo ello, más allá de las aportaciones en las que se destaca el papel de tú y usted como representantes de la solidaridad y el poder respectivamente, se han iniciado en las últimas décadas varias vías de análisis de la realidad lingüística que conceptualizan el hecho discursivo como un fenómeno mucho más dinámico y complejo. Esta actividad del habla, sujeta a la negociación entre los participantes y el contexto, tampoco puede presentar una única dirección. Es decir, no sólo los cambios contextuales y situacionales, como dice Blas Arroyo 1995a, p. 240 «provocan modificaciones en la realidad lingüística, sino que con frecuencia determinados índices lingüísticos -y no lingüísticos- actúan como claves señalizadoras de una alteración en los cuadros comunicativos y participativos iniciales que permiten a los participantes la adopción de nuevas estrategias discursivas».

\section{1. «Poder»y «solidaridad» en el eje de las relaciones interpersonales}

A principios de la década de 1960 se desarrolló en Norteamérica la psicología social, lo que supuso el acercamiento al fenómeno lingüístico desde la consideración social del lenguaje, alejándose, en este sentido, de las corrientes «inmanentistas» que ampliamente se habían constituido al amparo del estructuralismo y del funcionalismo. Unos años antes nacerá la perspectiva sociolingüística, en la cual el estudio de las formas de trato ocupará un lugar privilegiado.

Dentro de este contexto inicial de cambio de rumbos en el enfoque lingüístico hay que situar el trabajo pionero de dos psicolingüistas norteamericanos, Roger Brown y Albert Gilman, quienes fijaron para la li- 
teratura posterior del tratamiento los términos «poder»y «solidaridad» como resultado de las conclusiones de su investigación en varias lenguas del mundo, especialmente las indoeuropeas, al igual que otras pertenecientes a troncos lingüísticos de África y Oriente. Sin embargo, la base teórica que sustenta las hipótesis de Brown y Gilman puede encontrar sus antecedentes en otros estudios que abordaban algunos esquemas del comportamiento interpersonal. En efecto, algunas ideas se atisban en Goffman 1956, quien habla de los conceptos de «autoridad»y «afecto»; Leary 1957, por su parte, se refiere a «poder»y «afiliación» (quizá el más próximo al de «poder» y «solidaridad» de Brown y Gilman) o Heider 1958, quien usa los términos «desagrado» y «agrado» (disliking/liking) para catalogar también los niveles de la relación social.

Las conclusiones más destacadas del importante e influyente artículo de Brown y Gilman 1960, p. 253, es que en las lenguas investigadas el tratamiento está marcado, aunque no exactamente de la misma forma, por lo que llamaron dimensiones de «poder»y «solidaridad». Las abreviaturas latinas $T(t u)$ y $V$ (vos) representarían los usos pronominales en las diferentes lenguas. De esta forma, $T$ hace referencia al $t u ́$ /vos español, $t u$ francés o $d u$ del alemán; $V$, por su parte, engloba al usted, vous o sie en dichas lenguas respectivamente. Desde la perspectiva empleada por estos autores, los términos «poder»y «solidaridad» son definidos como:

«Poder»: Se puede decir que una persona tiene poder sobre la otra en la medida en que es capaz de controlar la conducta del otro (por medio de su riqueza, fuerza física, rol institucionalizado en la iglesia, el ejército, una organización económica, o dentro de la familia). El poder es una relación entre por lo menos dos personas; y es no recíproco en el sentido de que ambas no pueden tener poder en la misma área de conducta (Brown y Gilman 1960, p. 255).

«Solidaridad»: La solidaridad puede ser simétrica o recíproca, volviéndose $V$ más probable a medida que la solidaridad disminuye. La solidaridad $T$ alcanza un máximo de probabilidad en el tratamiento entre hermanos mellizos o en los soliloquios de un hombre consigo mismo (Brown y Gilman 1960, p. 258).

La concepción de ambos ejes se enmarca en una dimensión semántica; es decir, ambos pronombres aparecen en la interacción como producto de la covariación entre el pronombre empleado y la relación objetiva entre el hablante y el destinatario. O lo que es lo mismo, dependiendo de las características sociolingüísticas de los interlocutores, el tratamiento estará regido por uno de los dos ejes. El punto de partida fue el análisis llevado a cabo acerca de la evolución pronominal durante el siglo XIX y gran parte del XX. Entonces se pudo constatar cómo hasta mediados del xx había prevalecido el eje del poder, mien- 
tras que a partir de la segunda mitad del mismo (en una sociedad mucho menos jerarquizada y estratificada como lo había sido hasta entonces) se encuentra, por el contrario, una preferencia por las formas con $T$ (solidarias) ${ }^{11}$.

La norma de la solidaridad apareció -según explica la investigación de Brown y Gilman 1960- para tratarse las personas de igual estatus. Así, si eran de estatus alto se dirigían un $V$ recíproco, mientras que si eran de las clases inferiores empleaban un $T$. No obstante, la evolución de las sociedades condicionó el tratamiento. Las personas bien de la clase alta, bien de la baja, hacían uso de $T$ y del $V$ mutuos usándose el primero para tratar a los hermanos, a los esposos, a los íntimos, a los conocidos, y el segundo para dirigirse a los extraños o a nuevos conocidos. Después de una serie de consideraciones sobre algunas combinaciones de trato en «conflicto», Brown y Gilman dicen que la solidaridad aparece entre personas de clase alta $(T)$ y de clase baja $(T)$, al igual que entre individuos pertenecientes a clases sociales distintas, altas y bajas o bajas y altas $(T)$. En el caso contrario, si los hablantes consideran que no hay rasgos de solidaridad, prevalecería un ( $V$ ) mutuo entre personas de clase alta y un ( $V$ ) mutuo entre personas de clase baja; también se daría esta díada entre sujetos de clases altas hacia las bajas y de las bajas hacia las altas.

Parece evidente que tanto el poder como la solidaridad están encuadrados en la esfera de las relaciones sociales. La solidaridad ocuparía el eje horizontal de las mismas, mientras que el poder estaría en el vertical. En el caso de la primera surgen ciertos condicionamientos entre los interlocutores que hacen que estos puedan sentirse de manera distinta en función del tipo de hablante y las circunstancias específicas de cada acto comunicativo. Para Brown y Gilman 1960 los elementos que influyen en que aparezcan síntomas de solidaridad social son de diversa naturaleza: tener una misma profesión, jugar al mismo deporte, pertenecer al mismo sexo o grupo de edad, ser de la misma familia, partido político, religión, país, etc. Y todo ello dado que «la gente que tiene más contactos entre sí, comparte más ideas y gustos, experimenta mayor atracción y, por tanto, tiende a tener más contactos» (Weinerman 1976, p. 47). Esta misma investigadora, por ejemplo, afirma que parece más adecuado hacer una redefinición en términos de complementariedad antes que de oposición y propone solidaridad y no solidaridad: «dos interlocutores que se conocen bien pueden tratarse mutuamente de $T$, aunque se odien, igual que dos interlocutores que se gusten. Por otra parte, dos extraños generalmente se tratan de $V$, lo que no implica que no se gusten sino que no se conocen. Este problema, que no ha sido explicado en ninguno de los estudios realizados hasta el

\footnotetext{
11 La forma solidaria (tú) en español también ha recibido la denominación de "pronombre igualitario» o de «intimidad». Cf. Marín 1972.
} 
momento es, a nuestro parecer, una falla importante del esquema conceptual de Brown»(Weinerman 1976, p. 78) ${ }^{12}$.

Teniendo en cuenta estas consideraciones y la combinación de las formas diádicas sobre todo, podemos distinguir tres grados en el trato social $^{13}$ :

a) Relaciones diádicas asimétricas no recíprocas: es uno de los esquemas más tradicionales en el tratamiento: el superior utiliza una forma de confianza (tú), mientras recibe un trato de respeto por parte del inferior (usted). Son las establecidas entre profesor/alumno, jefe/empleado y similares. Es la actitud, según este esquema, del presidente Rodríguez Zapatero.

b) Relaciones diádicas simétrico-recíprocas: se da un tratamiento igual entre los interlocutores bien ya sea desde el tú, bien ya sea desde el usted. Su aparición estará condicionada por los factores psicosociales antes señalados. Corresponde a la relación entre amigos, esposos, entre hermanos (tú); frente a situaciones formales como la ventanilla de un banco, juicios, consultas de médicos... que propiciarían el usted. Es lo que se debía esperar del jefe del Gobierno, quien violó esta conducta.

c) Relaciones «preestablecidas» o «condicionadas»: se trata ahora de reflejar la fluctuación existente en los esquemas de tratamiento. El uso de tú o de usted se ve condicionado por razones expresivas, de énfasis en muchos casos, de afirmación de la autoridad, porque el medio así lo impone ( «es norma de la casa tratar a todo el mundo de usted», se dice en muchos contextos), por razones protocolarias, etc. Aquí estaría también la interacción comunicativa que propiciaba el contexto formal de la entrevista presidencial.

El esquema teórico de Brown y Gilman lo vemos reconvertido en una interpretación de la «distancia social» tal y como la plantea Escandell Vidal 2005. Para esta autora existen dos dimensiones diferentes: una re-

12 Debo hacer notar en esta referencia que Weinerman alude, en realidad, al trabajo de Brown 1965/1972, concepción que coincide, en esencia, con la de Albert Gilman también en el artículo de 1960.

${ }^{13}$ Blas Arroyo 1995ํㅜ , p. 231 resume también las díadas propuestas basadas en los términos «poder» y «solidaridad» de Brown y Gilman 1960. Según este investigador, tendríamos A): relaciones presididas por el "poder» (1. Trato asimétrico: superior dirige $\mathrm{T}$ al inferior y recibe $\mathrm{V}$ de éste; 2. Trato simétrico: superior e inferior se dirigen V mutuamente); B): relaciones no presididas por el «poder» (1. Trato solidario (simétrico): ambos interlocutores intercambian T; 2. Trato no solidario (simétrico): ambos interlocutores intercambian v). Téngase en cuenta que para este autor «el polo opuesto al poder en las relaciones interaccionales no es exactamente la solidaridad, como suele afirmarse, sino más bien la ausencia de ese factor de control entre unos participantes y otros, es decir, el no poder». Estaríamos, en palabras suyas, ante dos conceptos «ambiguos» (Blas Arroyo 1995a, p. 235). 
lativa al grado de conocimiento previo entre los interlocutores y otra que apunta hacia la posición que ocupan los mismos en la escala social. En estos dos casos los denomina «eje de la jerarquía» el primero y «eje de familiaridad» el segundo. ¿Cómo aparecen definidos cada uno de ellos? Según Escandell Vidal 2005, pp. 58-61:

a) Eje de la jerarquía: está situado en el eje vertical y tiene que ver con la posición que ocupa cada hablante en la escala social. El poder relativo que cada uno ejerce sobre el otro es la base de esta dimensión. La relación puede ser simétrica (mismo lugar de la escala) o asimétrica (diferencias en la posición social por parte de los interlocutores). Para la evaluación de la jerarquía hay que tener en cuenta dos parámetros: las características inherentes o físicas (edad, sexo, raza, casta, clan...) y los roles sociales (papel desempeñado por cada individuo dentro del grupo). En este último caso destacan los roles diádicos del tipo jefe/empleado, médico/paciente, cliente/camarero, policía/ciudadano, maestro/discípulo, cura/feligrés, etcétera.

b) Eje de la familiaridad: conceptualizado en el eje horizontal de las relaciones, viene sustentado por dos dimensiones: el grado de conocimiento previo entre los interlocutores y el grado de empatía. Por su propia naturaleza, bien prevalezca una o la otra, la relación suele ser siempre simétrica y la aparición de $T$ es lo habitual, a lo que se suma que la posibilidad de abordar ciertos temas más familiares, cotidianos, cercanos o personales, además de otros aspectos propios de los registros más íntimos. Escandell Vidal 2005, p. 61, dice, en este sentido que: «cuanto más alejados están dos interlocutores, en cambio, más distancia lingüística hay entre ellos: se prefieren las formas de tratamiento de deferencia y la interacción no suele tocar temas privados».

La conclusión de toda esta visión de la dimensión social trae consigo una combinación de ambos ejes en la cual podemos permitirnos

situar a los participantes como diferentes puntos en un plano, según los lugares relativos que ocupen con arreglo a las dos dimensiones que hemos comentado. Dos puntos muy alejados tanto en el eje de jerarquía como en el eje de familiaridad implican una interacción con mucha distancia; dos puntos muy próximos, en cambio, sugieren una interacción cercana (Escandell Vidal 2005, pp. 61-62).

Todo ello trae consigo, por tanto, que, cuanto más distancia social haya, mayor será, previsiblemente, la distancia lingüística que pueda establecerse entre los interlocutores. El público y el presentador de Tengo una pregunta para usted respetaron el «contexto comunicativo» (una larga entrevista en la televisión estatal con un alto contenido ceremonial). 
La ruptura de una de las partes intervinientes en esta interacción vino, precisamente, del lado del que representa una gran dimensión del «poder» que utilizó un igualitario tú nada esperado, a juzgar, como se ha podido comprobar, por la reacción crítica mayoritaria. Los rasgos inherentes a este contexto comunicativo-televisivo y el rango/rol social representado por el presidente del Gobierno español hacían presagiar un usted distanciador y protocolario acorde con la situación de formalidad. Pero no fue así.

La estrategia conversacional marcada por el presidente -o para algunos sugerida por sus asesores- radica en la utilización de un esquema más propio de lo coloquial (Briz Gómez 2001) que de lo verdaderamente formal o protocolario, dado el medio en el que la entrevista se produjo. En este sentido, expone Vigara Tauste 1992, p. 391, que los hablantes desarrollamos mecanismos que ella denomina "precauciones oratorias», las cuales apuntan hacia la necesidad de emitir mensajes y expresiones que sirvan de base a una mejor comprensión y colaboración entre los interlocutores. Y ello es así porque en definitiva se busca incentivar en muchas ocasiones un mecanismo de "persuasión" para adaptarse al otro y al ambiente, circunstancias que, en el caso de Tengo una pregunta para usted sólo se "pretendió» por una de las partes aunque, a juzgar por la reacción obtenida, fue un fracaso. La dirección del tuteo nunca tuvo una respuesta en la misma línea, pues los interlocutores jamás abandonaron el usted. Esas «precauciones oratorias» que indica Vigara Tauste 1992, p. 392, tuvieron su efecto en la conciencia y actuación lingüísticas de las cien personas que podrían tener interacción con el presidente, pues el rol jerárquico y el contexto de situación actuaron, bajo mi punto de vista, como dos factores clave.

\subsection{La cortesía verbal como marco sociopragmático del tratamiento}

El estudio de la «cortesía verbal» ha ocupado un lugar preeminente dentro de la pragmática, en particular con las tesis de Brown y Levinson 1978/1987, sin olvidar las propuestas teórico-metodológicas de Lakoff 1973 y Leech 1983. La consideración del fenómeno de la cortesía no se estudia simplemente desde la perspectiva lingüística, habida cuenta de que como mecanismo sociocultural exige para su correcta comprensión incursiones en distintos terrenos como la psicología, sociología, antropología social, lingüística, etc. La cortesía -tal y como expone Bravo 2001, pp. 300-303, una de las investigadoras que más profundamente la ha analizado para el español- puede catalogarse en tres aspectos: cortesía lingüística o comunicativa, estratégica y conversacional. Se indica, además, como hace la propia Bravo 2001, p. 301, una diferencia entre la cortesía «formal» y la «estratégica», en tanto en cuanto a la pri- 
mera corresponden todos aquellos elementos que ya están preestablecidos o ritualizados como son los saludos, tratamientos deferentes o normas protocolarias ${ }^{14}$. La cortesía estratégica, por el contrario, queda a merced del hablante (depende de su libre elección) en función del contexto situacional-comunicativo en el que se produzca el acto de habla $^{15}$. Es obvio que en este segundo caso el presidente optó por un modelo volitivo y, por lo tanto, utilizó ex profeso el tuteo general para con sus interlocutores, sin importarle el trato recibido ni otro tipo de parámetros contextuales o de distancia social que mediara entre ellos.

Las «normas de cortesía», e incluimos en éstas, como acabo de exponer, los saludos, las invitaciones, las órdenes, los contactos físicos, las despedidas, etc., son actos de tipo social (codificados en la mayoría de las lenguas) que vienen condicionados por reglas igualmente sociales, cuya variación será más o menos igual según la comunidad social en la que aquéllas tengan su aparición. En este sentido, entran en juego las llamadas reglas ceremoniales, y en particular los conceptos de «deferencia» $y$ «conducta» sociales descritos por E. Goffman 1956 y 1967. La «deferencia» implica, dentro del sistema pronominal del tratamiento, que los hablantes desempeñan en ocasiones un rol social o psicológico determinado frente al interlocutor, el cual a su vez adopta un papel concreto en el terreno de lo social. Ocurre a menudo en las entrevistas de los medios de comunicación, pero también en las entrevistas de trabajo, entre otras situaciones. Bien es cierto que emisor y receptor están unidos, en muchas ocasiones, por más de un rol, y así lo reconoce el propio Goffman 1956, p. 480: «un único acto de deferencia puede involucrar diferentes tipos de relación, como cuando un médico con un gesto paternal muestra autoridad sobre una enfermera, en su calidad de subordinada, pero también afecto en su calidad de mujer joven, dependiente de él en su calidad de hombre mayor capaz de dar apoyo». El grado de cercanía/distancia que establecen los interlocutores se presenta como pieza fundamental en esta concepción teórica de los actos sociales; es decir, la deferencia será más o menos simétrica o asimétrica en relación con los vínculos de distancia psicológica que exista entre emisor y receptor.

El estudio de la cortesía implica el análisis de la interacción social, dentro de la cual las formas de trato tienen buena parte de su explicación. Ahora bien, corresponde a dicho análisis poner de relieve las diferentes manifestaciones, las reglas y los mecanismos pragmáticos que cada comunidad de habla tiene a su alcance (factores individuales, contextuales o temas conversacionales), tal y como afirman Watts y otros

\footnotetext{
${ }^{14}$ Como por ejemplo, el uso de usted a los desconocidos en un programa de televisión o hacia personas mayores, tan usual en el contexto sociocultural hispánico.

15 En la concepción de la cortesía verbal se enmarca el llamado «principio de cooperación», tal y como señaló Grice 1975, que viene a decir que los hablantes deben ser cooperativos («sé cortés») para alcanzar el éxito comunicativo.
} 
1992. Por ello, estos aspectos deberían ser tratados sin perder de vista el papel que juegan los roles sociales de los interlocutores y el poder que los interactuantes mantienen entre sí. Esta concepción más amplia de la cortesía, por tanto, supone que la misma va más allá de los puros actos lingüísticos (cortesía verbal) y se propone, en este sentido, una «cortesía lingüística o comunicativa», que incluya tanto a los actos puramente verbales como a los no verbales (Bravo 2001, p. 300). Cortesía y formas lingüísticas de tratamiento o los llamados décticos sociales son un terreno en el que la interrelación de ambas resulta más evidente. Las sociedades, dice Escandell Vidal 2002, p. 137, organizan a sus miembros en función de su cultura, jugando en aquellas cada uno un rol que viene determinado por dos tipos de rasgos:

I) Propiedades macrosociales:

a) características: edad, sexo, posición familiar.

b) propiedades adquiridas: rango, título, posición social.

II) Actuación individual.

\subsubsection{Una nueva imagen}

En el estudio del tratamiento ha recibido una especial atención la interpretación «mecanicista basada en la oposición poder/solidaridad que tiende a dejar de lado el contexto sociocomunicativo y discursivo, los macro-actos de habla, la intención comunicativa y sobre todo, el concepto de imagen, que es uno de los principales factores que condiciona el uso de las formas de cortesía», según expone Serrano 2001, p. 265. En efecto, el último de los aspectos, el que se refiere a la «imagen», creo también que no ha sido lo suficientemente desarrollado en aplicación al sistema pronominal de trato, en el que ha pesado más la concepción antes indicada (cf. supra 2.1 y su estela teórica y práctica del modelo de Brown y Gilman 1960). La idea de la imagen, situada dentro de la cortesía verbal, hay que relacionarla con la proyección del individuo dentro de la sociedad en la que se inserta. Para Brown y Levinson la cortesía se erige en el eje central del comportamiento de los individuos, en tanto en cuanto estos desean mantener una imagen (face) pública y privada. Y esta imagen siempre comporta dos factores: uno «negativo»y otro «positivo» (Brown y Levinson 1987, p. 13):

Central to our model is a highly abstract notion of face which consists of two specific kinds of desires (face-wants) attributed by interactants to one another: the desire to be unimpeded in one's actions (negative face), and the desire (in some respects) to be approved of (positive face). This is the bare bones of a notion of face which (we argue) is universal, but which in any particular society we would expect to be subject of much cultural elaboration. 
Havertake 1994, p. 19, por su parte, señala que postulando la validez universal de la teoría de Brown y Levinson 1987 en lo que se refiere al concepto de imagen, se justifica la hipótesis de que la interacción social en general y la verbal en particular impone a los participantes la norma de que respeten mutuamente, como se indica en la cita precedente, lo que Brown y Levinson 1987 denominan face-wants 'necesidad de imagen'. Todo hablante persigue siempre, no obstante, un equilibrio para intentar proteger su personalidad, al igual que la del otro. Los interlocutores buscamos una imagen social que muchas veces viene acompañada por un ansia de autoestima que deseamos que sea respetada y asumida por los demás, según Brown y Levinson 1987, p. 13. Como es obvio, la aplicación del modelo teórico de Brown y Levinson ha chocado con algunas fallas y reticencias de tipo teórico-metodológico en distintas comunidades y culturas ${ }^{16}$. El principal escollo se encuentra en la concepción de la «imagen» como hecho universal (Carrasco Santana 1999; Bravo 2001, pp. 305-308) y su constatación en diferentes culturas tanto occidentales (Wierzbicka 1985; Sifianou 1992; Kerbrat-Orecchioni 1994; Bravo 1999; Boretti 1997, 2001 y 2003; Hernández Flores 2002) como orientales (Matsumoto 1988; Ide 1989; Gu 1990; Ide y otros 1992; Mao 1994). Frente a esta posición ${ }^{17}$, están aquellos que defienden la consideración del hecho «sociocultural» en el cual tienen lugar las acciones de cortesía. En el análisis llevado a cabo por Bravo 2004, quien remite a otros muchos que abordan este asunto, la investigadora argentina pone de manifiesto la necesidad de incorporar el elemento sociocultural a los trabajos de cortesía en diferentes comunidades de habla y es partidaria, en este sentido, de utilizar una metodología lo suficientemente flexible que permita al especialista dar cuenta de la diversidad cultural y social, del estudio del propio evento o del contexto comunicativo. Todo ello redundará en la circunstancia de que una situación determinada pueda ser catalogada como «cortés» (Bravo 2004, p. 27). Los trabajos hechos en numerosos lugares del mundo resaltan que no todos los grupos sociales tienen el mismo concepto de imagen social y por tanto tampoco utilizan las mismas estrategias ${ }^{18}$. Bravo 2004 pone de relieve que en la «actividad de cortesía»-como un tipo de «actividad de imagen»- se en-

${ }^{16}$ Holtgraves y Yang 1990 (cit. por Carrasco Santana 1999, p. 33, nota 37) ponen de relieve, por ejemplo, cómo actúan el grado de confianza y el poder relativo en el coreano y el japonés, a diferencia de lo que ocurre en las sociedades occidentales y, especialmente, en la española.

17 Otros autores, sin embargo, indican que el modelo de Brown y Levinson 1987 es acertado, si bien merece algunas modificaciones, tal y como señala Kerbrat-Orecchioni 2004, p. 41.

18 Un estado de la cuestión sobre la cortesía en español se halla en Oralia. Análisis del discurso oral, Arco/Libros e ILSE, Madrid. Dentro de este volumen cf. Iglesias Recuero 2001. Muchas otras cuestiones aquí sólo esbozadas pueden encontrarse también en Bravo y Briz (eds.) 2004. 
cuentra lo que ella denomina «imagen básica», la cual daría cuenta «de una imagen consensuada y extendida a la sociedad de pertenencia que estaría «supuestamente» en conocimiento de los hablantes de una lengua, ya sea que la asuman o no» (Bravo 2004, p. 28) ${ }^{19}$. La imagen básica hay que entenderla como un aspecto de la identidad social del individuo y la misma puede verse afectada por los comportamientos comunicativos que se desarrollan en la interacción: será puesta en entredicho si se produce una «amenaza», adquiere realce (cortesía valorativa), protegida (cortesía por atenuación) o atacada (descortesía), etc. De esta forma, los comportamientos comunicativos que de una manera u otra afectan en la imagen social son las actividades de imagen. Si estas actividades son positivas para la imagen del otro, pasan a ser actividades de cortesía.

La introducción de los conceptos de «imagen básica» y de «imagen de los roles» me parece muy acertada si se desean evaluar comportamientos que se juzgan como descorteses socialmente. En el caso que nos ocupa, el rol del presidente del Gobierno está encuadrado claramente dentro de las dimensiones del poder, del que gobierna frente a sus gobernados, del que representa una alta jerarquía frente a los que ocupan, por el contrario, una amplísima base social. Público y presentador le brindaron ejemplos de cortesía y de rol sociales en el contexto comunicativo televisivo: usaron la forma usted y respetaron los turnos de palabra establecidos por el moderador del programa en esta modalidad de entrevista.

Así pues, desde la perspectiva de la imagen personal, las formas de tratamiento implican que hay una actitud social hacia el interlocutor que condiciona la aparición de ciertas estrategias y usos particulares al afecto, conducentes a fundamentar, en cada situación de habla, las características de la protección o violación de esa imagen positiva (Serrano 2001, p. 267). Está claro que el tratamiento en la mayoría de las lenguas refleja la existencia de roles sociales y que estos, del mismo modo, pueden sufrir alteraciones; es decir, llegada la ocasión pudieran entenderse como actos que van contra la imagen considerada descortés por parte del interlocutor. En el caso del presidente, creo que ha sido la ruptura de esa fina barrera entre lo considerado «cortés»y «no cortés» lo que ha provocado, en general, una desaprobación social y periodística. Paradójicamente, el componente sociopragmático y contextual que el presidente rompió al tutear al aforo de cien personas fue lo que produjo un daño en su imagen social. Una supuesta «falsa actuación» por parte del presidente y un exceso de «aparente cercanía» del mismo no

19 Dice Bravo 2004, p. 29 a este respecto que «se comprende el contexto que al usuario de una lengua le permite atribuir a una persona calificativos tales como los de cortés, descortés, maleducado, amable, cordial, etc. Partiendo de esa imagen básica y teniendo en cuenta una multiplicidad de roles que los hablantes cumplen en su vida cotidiana, se habla también de imágenes de los roles». 
fueron bien recibidos, ya que violó, de alguna manera las reglas básicas de la cortesía en ambas direcciones. Escribe en este sentido Almeida 2003, p. 160 al comentar el modelo de Brown y Levinson que la cortesía negativa es la que predomina en las sociedades de la cultura occidental e industrializada y que es, además, la que aparece en las relaciones entre desconocidos o entre personas con poco trato. Por otro lado, entre los grupos sociales bajos predomina la cortesía positiva, mientras que en los grupos alto y medio, por el contrario, domina la negativa. Así lo exponen Brown y Levinson 1982, p. 245:

In general we have a hunch that all over the world, in complex societies, dominated groups (and sometimes also majority groups) have positivepoliteness cultures; dominating groups have negative-politeness cultures. That is, the world of the upper and middle groups is constructed in a stern and cold architecture of social distance, asymetry, and resentment of impositions, while the world of the lower groups is built on social closeness, symmetrical solidarity, and reciprocity.

El nivel de confianza demostrado a través de este tú se vinculó con un grado de proximidad realmente «inexistente» al tratarse de un plató de televisión en un programa en directo, frente a una audiencia cifrada en millones de telespectadores. En otros contextos, como se sabe, la confianza se relaciona con una situación de proximidad (íntima) o de acercamiento al grupo y, por lo tanto, será valorada positivamente. El rol presidencial frente al rol del «ciudadano de a pie» no encajaba en las prácticas habituales del tratamiento en la sociedad española y, por todo ello, fue considerado como un acto negativo de cortesía comunicativa en este contexto. No obstante lo anterior, es fácilmente perceptible que la evolución social y democrática experimentada en España en las últimas décadas ha traído consigo, en este terreno, una clara simplificación del sistema de relación interpersonal lo que ha permitido, consecuentemente, una mayor flexibilización de las relaciones entre la estratificación social. En términos parecidos se refiere Blas Arroyo 1994, p. 21, cuando comenta los usos de tú y usted en el español contemporáneo. En el primer caso, este pronombre (tú) no sólo abarca los contextos que tienen que ver con las relaciones familiares y amistosas, sino que se convierte en todo un marcador de proximidad grupal, lo cual le permite traspasar su ámbito de uso a otros dominios en los que ciertos atributos de los interlocutores pueden condicionar a uno de ellos (tratamiento asimétrico) o a ambos (tratamiento simétrico) a su utilización. Y así se comprueba, cada vez más, en numerosas interacciones y contextos comunicativos presididos por el tú. Dice Blas Arroyo 1994, p. 21, que

el progreso que el empleo de tú ha experimentado en la mayoría de las comunidades de habla hispánica, podría ser analizado como un reflejo de la 
tendencia creciente en sociedades modernas y democráticas, cada vez más permisivas, a limar prejuicios y jerarquizaciones sociales, lo que ha contribuido a una valoración crecientemente positiva del tuteo como forma de tratamiento adecuada -incluso cortés, como estamos viendo- en situaciones cada vez más numerosas ${ }^{20}$.

Similar situación describe ampliamente Carrasco Santana 1999, p. 34, para el cual no es que desaparezcan -en este contexto- los patrones tradicionales de la cortesía social manifestada a través del usted, sino que el concepto de la misma, en la sociedad española, al menos, está cambiando, lo que ocasiona que la interacción

se manifiesta en una menor utilización de fórmulas convencionales y ritualizadas de cortesía, en la progresiva desaparición de fórmulas de tratamiento, en la extensión del tuteo en situaciones en que no existe familiaridad, etc., lo que está produciendo un progresivo cambio cualitativo en las selecciones corteses que hace que se evite, cada vez con más frecuencia, exteriorizar verbalmente la subordinación al otro por razón de autoridad. Esto no significa una desaparición de la cortesía, sino una adecuación de la misma al contexto social, que actúa con dos objetivos: procurar un mayor acercamiento entre los interlocutores, que facilite un ambiente más armonioso y distendido, y, por otra parte, proteger la imagen de quien está sometido a la autoridad no manifestando supeditación al otro.

Subyace en todo este asunto el complejo mundo de las «distancias sociales» que es básico para entender, en este terreno, el grado de cortesía. Haverkate 1994 considera como actos de habla corteses el saludo, el cumplido, el agradecimiento, la disculpa y los actos comisivos. Entre las funciones interactivas del saludo, el que ahora más me interesa, está el hecho de que sirva "para establecer o confirmar una determinada relación interaccional, tal como se define por factores como posición social, grado de intimidad y afecto» (Haverkate 1994, p. 85), elementos todos determinantes, como es bien conocido, en la selección del tratamiento no sólo en el primer momento de la interacción (que puede ser el saludo), sino también a lo largo del desarrollo discursivo. Dentro de estas formas cobra un gran valor la distancia social ${ }^{21}$ que se opera a tra-

${ }^{20}$ En el extremo opuesto, dice Blas Arroyo 1994, p. 22, «la elección de usted vendría a representar el mantenimiento de estrategias más conservadoras y tradicionalmente más prestigiosas, relacionadas con la denominada cortesía negativa [...] la imagen más común de la cortesía en las culturas occidentales coincide precisamente con esta cara negativa del concepto».

${ }^{21}$ Blas Arroyo 1995a, p. 237, cuando pone en duda el mantenimiento de la oposición poder/solidaridad de Brown y Gilman 1960 hace notar que el concepto de «poder», por ejemplo, habría que entenderlo más hoy en día en unos términos que la propia dinámica social ha ido cambiando. Así como en épocas pasadas algunas instituciones jerarquizadas como la familia imponían el uso asimétrico entre miembros generacionalmente distintos, éste se trasladaba también a otras instancias sociales en las que se identificaba a la persona mayor con un superior. En la actualidad, dice este investigador, «no parece tan claro que el carácter respetuoso 
vés de los esquemas salutatorios en numerosas lenguas. El segundo de los planos, el vertical, es el que se dirige a las relaciones jerárquicas, de poder o autoridad (como la que aquí se comenta). Afirma Haverkate 1994, pp. 86-87, en este sentido, que

en una lengua como el español, que no cuenta con un amplio sistema de expresiones honoríficas, como, por ejemplo, el japonés, el factor de la distancia social repercute, fundamentalmente, en la selección del pronombre de tratamiento cortés. Así, se establece una oposición entre las fórmulas de solidaridad ¿̇qué tal? y ¿qué hay?, por una parte, y la fórmula de distanciamiento ¿cómo está usted?, por otra.

Está claro que en ningún momento en la situación formal de la entrevista presidencial poco interesó que afloraran los contenidos emocionales del mensaje, aunque en alguna ocasión sí que estuvieron presentes y, por tanto, se cumplía así la primera de las reglas señaladas por Lakoff 1973 y 1975, citado por Almeida 2003, p. 159; Blas Arroyo 1994, p. 13; Escandell Vidal 2002, pp. 142-143. Para la investigadora británica el principio de cortesía está organizado en función de tres reglas básicas:

R1: formalidad: mantener la distancia.

R2: deferencia: dar opciones, dejar elegir.

R3: camaradería: mostrar simpatía.

La primera de ellas apunta a la cortesía formal que supone establecer una distancia ( $\dot{c}$ usted?) social entre emisor y receptor cuyo objetivo es eliminar el componente emotivo del mensaje; la segunda permite (real o convencionalmente) que el destinatario haga una elección determinada, como si su estatus fuera superior al del hablante; y la tercera se lleva a cabo entre iguales, en la que se expresan sentimientos de camaradería (Almeida 2003, pp. 159-160). Parece claro que el presidente recibió «protocolariamente» la R1, mientras que él optó por utilizar un grado de «camaradería» y cortesía con la R3, al emplear tú conscientemente para estrechar vínculos con su audiencia.

\subsection{El «usted» de la oposición}

La expectativa creada por la primera edición de la entrevista televisiva se vio incrementada por la segunda, dado que obtuvo, como ya dije al principio, mayor número de espectadores. Los ingredientes para al-

que, sin duda, posee todavía muchas veces el tratamiento de usted hacia las personas mayores sea una consecuencia directa del control psicosocial que éstas ejercen sobre los miembros más jóvenes de la sociedad» (1995a, p. 237). 
canzar tal éxito periodístico y televisivo eran obvios: el presidente del Gobierno frente al líder del mayor partido de la oposición política en España. Es decir, PSOE frente a PP. En esta ocasión, el representante del llamado «centro derecha» (el Sr. D. Mariano Rajoy) no se apeó en ningún momento del usted, circunstancia que fue -en sentido contrario a como he recogido en las opiniones periodísticas- alabada por unos o silenciada por otros. El Sr. Rajoy utilizó «cortésmente» un usted claro y rotundo: «Gano bastante más que usted» respondió a una interlocutora al ser preguntado por su sueldo. En un amplio análisis de su participación televisiva del que informa El Pais, se resalta que Rajoy «no cometió la equivocación de tutear a sus interlocutores, como hizo el presidente del Gobierno [...]» [El País, 21-04-2007, p. 29], mientras que en $A B C$ un psicólogo opina que "Rajoy se dirigió en todo momento de "usted" a cada persona del público que le preguntó, en consonancia con el tono respetuoso que quiso imprimir a su exposición» [ABC, 21-04-2007, p. 10]. Este mismo especialista, por el contrario, dice del presidente que «En lo verbal, se decantó por el "tuteo" que en algún caso forzaba la cercanía a pesar de la distancia física» [ABC, 21-04-2007, p. 10]. Otras opiniones, en fin, van en la misma dirección: «Bueno, pues Mariano Rajoy sí lo hará [tratar de usted al público]. El líder del PP va dispuesto a guardar las debidas normas de educación aunque luego se dirija a quienes le pregunten por su nombre de pila» [http://www.diariocritico.com, 24/04/2007].

El mismo presidente había manifestado a un grupo de periodistas que se sentía más cómodo utilizando el $t u^{22}$. Al contrario de lo que ocurre en las sesiones parlamentarias, donde lo habitual es el uso de usted y el honorífico (Su) Señoría, Señor, Señora, etc. En estos últimos casos la gramaticalización que se ha operado es evidente, en tanto en cuanto estas formas son el resultado del proceso de las estrategias de cortesía que implican las características sociales de los sujetos a las que representan. La deferencia social contenida en estos honoríficos - respetada de modo general en los actos ceremoniosos o protocolarios- hace que estas unidades estén «íntimamente relacionadas con las características sociales de los participantes y con ciertas convenciones adquiridas para el uso de formas verbales, por ejemplo el de usted como forma ligada a las relaciones de poder», según manifiestan Irvine 1995, pp. 8-9 y Serrano 2001, p. 269.

${ }^{22}$ Interesante es, no obstante, la asociación que se hace entre las formas de tratamiento y las ideologías políticas que alientan la aparición de uno u otro esquema en una lengua dada. En este sentido la vinculación se haría más evidente al relacionar tú (= ideología de izquierdas) y usted (= ideología de derechas). Algo similar ha ocurrido, por ejemplo, con el uso y el fomento que desde el «poder político-ideológico» se ha llevado a cabo en Hispanoamérica en relación con el tú y el vos. En este último caso, la dicotomía se basa en la oposición liberalismo/nacionalismo o derechas/izquierdas. Uno de los casos más ilustrativos es el de la revolución comunista en la isla de Cuba que ha fomentado el uso del tuteo, mientras que las dictaduras militares favorecían el voseo como ejemplo de nacionalismo. Cf. Lenarduzzi 1999, p. 246, y para cuestiones referidas a lengua y marxismo Marcellesi y Gardin 1979, pp. 108-136. 


\subsection{Nuevas propuestas, nuevos análisis}

Los párrafos anteriores han mostrado sucintamente algunos de los puntos de vista o teorías más reconocidos en los que es posible situar el contexto de las formas de trato y el fenómeno de la cortesía. Me gustaría detenerme en dos de los trabajos de Blas Arroyo, puesto que este investigador introduce varias perspectivas muy sugerentes en el acercamiento a este tema pronominal y que expongo a continuación a modo de resumen final. En el primer estudio (Blas Arroyo 1994) pone de manifiesto cuáles son las principales teorías sobre el fenómeno de la cortesía y la explicación, desde esta perspectiva, que merecen las formas de trato. En el segundo (Blas Arroyo 1995a) se lleva a cabo un análisis crítico y revisionista de los conceptos de «poder»y «solidaridad» ${ }^{23}$, según el modelo de Brown y Gilman 1960. Así está, como he destacado, la concepción de las máximas pragmáticas de Lakoff 1973, Leech 1983 y su retórica interpersonal, al igual que la de Brown y Levinson 1978/1987 y la idea de face con carácter universal. Blas Arroyo 1994, pp. 24ss. muestra, además, algunas teorías que ponen en duda el tratamiento epistemológico de la cortesía, pues en opinión de estos trabajos «se alejan considerablemente del conocimiento implícito que los individuos de una determinada sociedad tienen de ese mismo fenómeno» (1994, p. 24). En esta corriente de pensamiento se encuentran los estudios de Janney y Arndt 1992 que han propuesto la noción de «tacto» ${ }^{24}$ frente a la de «cortesía»; Fraser 1990, quien señala que los participantes en la interacción establecen una especie de contrato conversacional en el que la cortesía es la esencia de ese contrato ${ }^{25}$; Watts 1989 y 1992, por su parte, establece que el fenómeno de la cortesía se acerca más a las intuiciones que los hablantes tienen sobre la misma, por lo que propone el concepto de politic behaviour ${ }^{26}$ 'socialmente aceptable'. La perspectiva del in-

\footnotetext{
${ }^{23}$ Refiriéndose a estos dos conceptos Blas Arroyo 1995a, p. 235 dice: «Esta concepción de los sistemas pronominales de tratamiento presenta además otra importante debilidad. La propia caracterización de ambos ejes y su suficiencia para dar cuenta de las complejas relaciones psicosociales que con frecuencia van asociadas en la actualidad a las formas seleccionadas por los hablantes constituyen dificultades añadidas». Más adelante añadirá que el análisis de tú y usted, teniendo en cuenta estas premisas, debe tener una presentación cuidadosa en lo que toca a las diferentes dimensiones socioculturales que actúan en el seno de cada comunidad (1995a, p. 236).

24 «Actuar con tacto desde un punto de vista interaccional no significa sólo seguir un comportamiento social adecuado, esto es, ajustado a las normas sociolingüísticas imperantes en la comunidad, sino que va más lejos. Mediante el concurso del tacto, el hablante desarrolla estrategias y técnicas destinadas a fortalecer las relaciones interpersonales con los demás hablantes» (Blas Arroyo 1994, p. 24).

${ }_{25}$ La cortesía, según Fraser 1990, p. 233, es «un estado de cosas que los hablantes esperan que se produzca espontáneamente en cualquier conversación» (Blas Arroyo 1994, p. 27).

${ }_{26}$ «El carácter de este comportamiento no marcado de la interacción verbal depende de la influencia que ejercen diversos factores como el tipo de actividad social desarrollada [...], los
} 
vestigador británico abre, sin duda, una nueva visión de las formas pronominales españolas (tú/usted) y su aparición sociopragmática también debe analizarse, por tanto, desde otra óptica. En este sentido, concluye Blas Arroyo 1994, p. 29 que

en el caso de tú y usted, esta posición teórica [se refiere a Watts 1989 y 1992] supondría abandonar la idea tradicional que veía estas formas como marcas de confianza y cortesía respectivamente y su sustitución por otra noción según la cual ambos pronombres constituyen inicialmente -al menos en el español actual- realizaciones de un comportamiento socialmente aceptable (politic behaviour) y a partir de ahí investigar cómo en cada agregado social concreto la interacción de los diversos factores contextuales mencionados arriba puede hacer que sean interceptados como manifestaciones corteses o, por el contrario, abiertamente irrespetuosas.

Desde la perspectiva de Watts, el tuteo presidencial puede considerarse, en efecto, como un acto no cortés, pues no fue "políticamente correcto» ni fue socialmente aceptado por la comunidad en la que se ha insertado la interacción y a la cual, además, iba dirigida.

\section{Conclusiones}

Como queda expuesto en las páginas anteriores, el complejo mundo de las formas de tratamiento admite -a la luz de las recientes teorías lingüísticas-interpretaciones y análisis de variada índole. En el caso que nos ocupa, he tratado de contextualizar, mediante la recopilación de los datos periodísticos y de la reacción pública (ya sea parcialmente mostrada a modo de ejemplo), cómo se ha visto y recibido el tratamiento pronominal a través de la forma tú. El presidente Rodríguez Zapatero empleó en televisión un modelo comunicativo que perseguía unos fines concretos: el acercamiento, la ruptura de las barreras que impone la cortesía social, procurando una «imagen de cercanía» que fue criticada por muchos (cf. en 1.3. el corpus periodístico recogido) al mostrar gestualmente frialdad y distancia. Las estrategias marcadas por el tú del presidente condicionan la imagen pública del mismo y, como consecuencia, su imagen positiva o negativa según las opiniones. Parece que el nivel de cortesía esperado -de gran distancia entre hablante y oyente- se rompió por una actitud deliberada. Y todo ello, además, cuando se daba un

acontecimientos de habla parciales en que se divide aquella [...], el grado en que los hablantes participan de un conjunto de expectativas culturales e informativas comunes y los niveles de poder y distancia social entre los participantes previos a la interacción» (Blas Arroyo 1994, p. 28). Esta idea de cortesía, que deja de ser universal -tal y como la concibieron Brown y Levinson 1987-, para hallarla sujeta a los condicionamientos socioculturales específicos de cada comunidad, es la que defiende Bravo 2004 entre otros. 
conjunto de hechos que respaldaba un alto nivel de cortesía social: entrevista televisada, cien interlocutores desconocidos, temática variada, etc. En una perspectiva más amplia que la que aquí recojo cabría preguntarse cuáles son las razones que empujaron al presidente a optar deliberadamente por la opción del tuteo, o por qué en este contexto no puede ser «cortés» el uso del tú por parte de un presidente del Gobierno. Se trata de una ¿imprudencia? al anteponer su interés personal (le gusta más el tú, tal y como manifestó) o fue más bien que él tenía otros presupuestos y pensaba que si era cortés al utilizar esta estrategia. Las reglas y mecanismos pragmáticos vinculados al rol social que cada individuo desempeña hacen también que nos preguntemos cuál era el rol esperado para un presidente o si es aconsejable, en este caso, que el mismo no recurra (o quizá sí) al tuteo en una aparición pública dentro del contexto sociocultural y comunicativo español.

De los datos y análisis expuestos aquí puedo indicar que el tuteo presidencial ha ocasionado un rechazo generalizado (desde distintas perspectivas y objetivos no sólo sociopragmáticos, sino también políticos y, por tanto en este ámbito, ideológicos) por parte de aquellos que consideraban que el «contexto de situación» merecía una aparición de la forma de tratamiento más protocolaria y distanciadora: usted, tal y como hizo, por el contrario, el Sr. Mariano Rajoy semanas después en el mismo programa. La decisión del presidente de utilizar un tú que rompería las barreras psicosociales y de "poder» (para muchos) entre emisor y destinatario -y el receptor en esta ocasión eran cien, pero representaban a millones de españoles (en realidad a toda la sociedad española)hay que catalogarla, dentro del contexto de la cortesía lingüística, como un acto estratégico o volitivo, en los términos ya indicados antes (Bravo 2001). En esta interacción la parte presidencial no acató las normas del rol social «esperado» que hubiera implicado la aparición del usted y, como consecuencia, provocó una actitud negativa. En el corpus recogido, se constata ampliamente una consciencia lingüística contraria al tú presidencial y, en este sentido, la «imagen pública» del jefe del Gobierno español no salió reforzada, pues su actuación -dada esta «anécdota» lingüística- le ha supuesto una gran crítica social y telegénica.

Eliminadas, así pues, las pautas contextuales que una situación de esta naturaleza exigía, el tú del presidente hay que considerarlo, más allá de un simple tropiezo o circunstancia irrelevante propia de una dinámica televisiva, como un claro ejemplo de que cuando las reglas sociales y comunicativas se rompen las consecuencias pueden provocar un mayoritario rechazo hacia el rol social, lingüístico y sociopragmático en el que estamos implicados los hablantes a través de la interacción y que, en numerosas ocasiones, representamos hacia nosotros mismos y hacia los demás. Desde otra perspectiva, ya aquí esbozada, la actitud decidida del presidente de tutear a sus interlocutores significa -en un contexto más 
amplio y de cambio- que el concepto de cortesía social en España está también experimentando una notoria transformación. En este sentido, y como contrapunto a la situación descrita hasta ahora, no se ve como algo negativo que en la propaganda electoral y en la mayoría de los mítines (al menos así ocurre en España) se recurra al tú como forma de acercar el mensaje político y la imagen del candidato al ciudadano, a la vez que con esta estrategia se le hace copartícipe del proyecto que se somete a consideración pública.

\section{REFERENCIAS BIBLIOGRÁFICAS}

\section{Lingüistica}

Almeida, M. (2003): Sociolingüistica, 2. ํㅡㄹ., La Laguna, Universidad de La Laguna.

Álvarez Muro, A. y Carrera de la Red, M. (2006): «El usted de solidaridad en el habla de Mérida», en Schrader-Kniffki, M. (ed.), La cortesía en el mundo hispánico. Nuevos contextos, nuevos enfoques metodológicos, Madrid-Frankfurt, Iberoamericana-Vervuert, pp. 117-130.

Blas Arroyo, J. L. (1994): «Los pronombres de tratamiento y la cortesía», $R e-$ vista de Filología de la Universidad de La Laguna 13, pp. 7-35.

-, (1995a): «Un ejercicio de sociolingüística interaccional: el caso de los pronombres de tratamiento en el español actual», Verba 22, pp. 229-252.

—, (1995b): «Tú y usted: dos pronombres de cortesía en el español actual. Datos de una comunidad peninsular», ELUA 10, pp. 21-44.

Boretti, S. (1997): Estructuras interrogativas. Análisis de actos de habla coloquiales, Buenos Aires, AZ.

—, (2001): «Aspectos de la cortesía lingüística en el español coloquial de la Argentina», Oralia 4, pp. 75-102.

-, (2003): "Cortesía, imagen social y contextos socioculturales en la variedad del español de Rosario, Argentina», en Bravo, D. (ed.), Actas del Primer Coloquio del programa EDICE. «La perspectiva no etnocentrista de la cortesía: identidad sociocultural de las comunidades hispanohablantes», Estocolmo, Universidad de Estocolmo. <www.edice.org $>$.

Bravo, D. (1999): «¿Imagen positiva vs. imagen negativa? Pragmática sociocultural y componentes de face», Oralia 2, pp. 155-184.

—, (2001): «Sobre la cortesía lingüística, estrategia y conversación en español», Oralia. Análisis del discurso oral 4, Madrid, Arco/Libros, ILSE, pp. 299-314.

-, (2004): «Tensión entre universalidad y relatividad en las teorías de la cortesía», en Bravo y Briz (eds.), pp. 15-37.

Bravo, D. y Briz, A. (eds.) (2004): Pragmática sociocultural: estudios sobre el discurso de cortesía en español, Barcelona, Ariel.

Briz Gómez, A. (2001): El español coloquial en la conversación. Esbozo de pragmagramática, Barcelona, Ariel.

Brown, P. y Levinson, S. C. (1978/1987): Politeness. Some Universals in Language Use, Cambridge, Cambridge University Press. 
Brown, R. (1965): Social Psychology, Nueva York, The Free Press (trad. esp.: «Las dimensiones fundamentales de la relación interpersonal», en Psicología social, Madrid, Siglo XxI, 1972, pp. 61-111).

— y Gilman, A. (1960): «The pronouns of Power and Solidarity», en Sebeok, T. A. (ed.), Style in language, Cambridge, M.I.T., Press, pp. 253-276.

CARrasco SANTANA, A. (1999): «Revisión y evaluación del modelo de cortesía de Brown \& Levinson», Pragmalingüistica 7, pp. 1-44.

ESCANDELL VIDAL, M. ํㅡ. V. (2002): Introducción a la pragmática, nueva edición actualizada, Barcelona, Ariel.

—, (2005): La comunicación, Madrid, Gredos.

FERNÁNDEZ, Mauro A. (2006): «Pronombres de segunda persona y fórmulas de tratamiento en español: una bibliografía», Lingüistica en la red. LinRed. $<$ www.linred.com>. (52 pp.).

Fontanella DE WeINBERG, M. ${ }^{\mathrm{a}}$ B. (1999): «Sistemas pronominales de tratamiento usados en el mundo hispánico», en Bosque, I. y Demonte, V. (eds.), Gramática descriptiva de la lengua española, vol. 1, Madrid, Espasa, pp. 1401-1425.

Fraser, B. (1990): «Perspectives on politeness», Journal of Pragmatics 14, pp. 219236.

Goffman, E. (1956): «The nature of deference and demeanor», American Anthropologist 58, 3, pp. 473-502.

—, (1967): «On face-work. An analysis of ritual elements in social interaction», en Interaction Ritual: Essays on Face-to-Face Behavior, Nueva York, Anchor Books, pp. 5-45.

Grice, H. P. (1975): «Logic and conversation», en Cole, P. y Morgan, J. L. (eds.), Syntax and Semantic. III. Speech Acts, Nueva York, Academic Press, pp. 41-58.

Gu, Y. (1990): «Politeness phenomena in modern Chinese», Journal of Pragmatics 14, pp. 237-257.

Hummel, M.; Kluge, B. y Vázquez Laslop, Ma E. (2010): Formas y fórmulas de tratamiento en el mundo hispánico, México, El Colegio de México.

Havertake, H. (1994): La cortesía verbal, Madrid, Gredos.

HeIDER, B. F. (1958): The psychology of interpersonal relations, Nueva York, John Wiley.

HeRnÁNDEZ Flores, N. (2002): La cortesía en la conversación española de familiares y amigos; la búsqueda del equilibrio entre la imagen del hablante y la imagen del destinatario, vol. 37, Aalborg, Institut for Sprog Internationales Kulturstudier, Aalborg Universitet.

Holtgraves, Th. y YAng, J. (1990): «Politeness as Universal: Cross-Cultural Perceptions of Request Strategies and Inferences Based on Their Use», Journal of Personality and Social Psychology 59, pp. 719-729.

IgLesias Recuero, S. (2001): «Los estudios de la cortesía en el mundo hispánico. Estado de la cuestión», Oralia. Análisis del discurso oral 4, Madrid, Arco/Libros, ILSE, 4, pp. 245-298.

IDE, S. (1989): «Formal forms and discernment: two neglected aspects of universals of linguistic politeness», Multilingua 8, 2-3, pp. 223-248.

—; Hill, B.; Carnes, Y. M.; Ogino, T. y Kawasaki, A. (1992): «The concept of politeness: An empirical study of American English and Japanese», en Watts y otros (eds.), pp. 281-297. 
IRvine, J. (1995): «Honorifics», en Verschueren, J. y Blommaert, J. (eds.), Handbook of Pragmatics, Amsterdam, Benjamins, pp. 1-22.

JANNEY, R. W. y ARNDT, H. (1992): «Intracultural tact versus intercultural tact», en Watts y otros (eds.), pp. 21-41.

Kerbrat Orecchioni, C. (1994): Les interactions verbales, vol. III, París, Armand Colin.

—, (2004): «¿Es universal la cortesía?», en Bravo, D. y Briz, A. (eds.), pp. 39-53.

LAKoff, R. (1973): «The Logic of Politeness; or, Minding Your P's and Q's», en Papers from the Ninth Regional Meeting of the Chicago Linguistic Society, Chicago, Chicago Linguistic Society, pp. 292-305.

LAKoff, R. (1975): Language and woman's place, Nueva York, Harper \& Row.

LEeCh, G. (1983): Principles of Pragmatics, Londres, Longman.

LENARDUZZI, R. (1999): «El voseo: uso, norma e identidad», en Calvi, Maria Vittoria y San Vicente, Félix (eds.), Palabras de acá y de allá. La identidad del español y su didáctica, V. III, Milán, Mauro Baroni editore, pp. 240-248.

LEARY, T. (1957): Interpresonal diagnosis of personality, Nueva York, Ronald Press.

MARCELLESI, J. B. y GARDIN, B. (1979): Introducción a la sociolingüistica. La lingüística social, Madrid, Gredos.

Marín, A. (1972): «El uso de tú y usted en el español actual», Hispania 54, pp. 904-908.

Matsumoto, Y. (1988): «Reexamination of the universality of face: Politeness phenomena in Japanese», Journal of Pragmatics 12, pp. 403-426.

MAO, L. 1994: «Beyond politeness theory: Face revisited and renewed», Journal of Pragmatics 21, pp. 451-468.

SERrAnO, M ${ }^{\mathbf{a}} \mathrm{J}$. (2001): «La deixis social en los usos pronominales de cortesía en español», Revue de Sémantique et Pragmatique 9, 10, pp. 265-280.

Sifianou, M. (1992): Politeness phenomena in England and Greece. A cross-cultural perspective, Oxford, Clarendon.

Vigara Tauste, A. M.ํㅗ (1992): Morfosintaxis del español coloquial. Esbozo estilístico, Madrid, Gredos.

WATTS, R. (1989): «Relevance and relational work: Linguistics politeness as politic behaviour», Multilingua 8, 2/3, pp. 131-166.

—, (1992): «Linguistic Politeness and politic behaviour: Reconsidering claims for universality», en Watts y otros (eds.), pp. 21-42.

Watts, R.; IdE, S. y Ehlich, K. (eds.) (1992): Politeness in Language. Studies in its History, Theory and Practice, Berlín, Mouton de Gruyter.

WeInerman, C. (1976): Sociolingüistica de la forma pronominal, México, Trillas.

WierzBickA, A. (1985): «Different cultures, different languages, different speech acts», Journal of Pragmatics 9, pp. 145-178.

\section{Periodística}

ARIAS VEGA, E. (2007): «El tuteo como compadreo político», en <http://www.diariocritico.com>.

Ballenato, G. (2007): «Gestos para el análisis», ABC, 4 de abril, p. 10. 
Belmonte, R. (2007): «Afrancesado, salvo en el recurso al tuteo a los entrevistadores», $A B C, 29$ de marzo, p. 25.

CAMAcho, I. (2007): «Ochenta céntimos», $A B C, 29$ de marzo, p. 5.

Gallego-Díaz, S. (2007): «Empeñado en un único propósito», El País, 21 de abril, p. 29.

García Abadillo, C. (2007): «Pero, ¿¿dónde toma el café el presidente del Gobierno», El Mundo, 29 de marzo, p. 22.

Gómez, R. G. (2007): «Los 100 de Zapatero», El País, 29 de marzo, p. 25.

JimÉnez BArCA, A. (2007): «Todo sobre ZP en TVE», El País, 1 de abril, p. 23.

MARCO, J. M. (2007): «Del tuteo a la emancipación», en <http://www.libertaddigital.com $>$.

MARTín FERrand, M. (2007): «Cien contra uno», $A B C, 29$ de marzo, p. 6.

Martínez, Á. (2007): «Un café, cuestión de Estado», ABC, 29 de marzo, p. 24.

MARTíneZ-SimanCAS, R. (2007): «Cien preguntas y Zapatero responde», El Mundo, 29 de marzo, p. 22.

Palomera, Esther L. (2007): «El café de 80 céntimos», La Razón, 29 de marzo, p. 15.

SÁnCHEZ, M. (2007): «Zapatero se paga un café a 70 céntimos en el Congreso», El Mundo, 29 de marzo, p. 20.

Soriano, D. (2007): «Los jóvenes no tienen preguntas», El Mundo, 21 de abril, p. 13.

Torquemada, B. (2007): «Rígido, frío e institucional», $A B C, 29$ de marzo, p. 26.

\section{En Internet}

http://www.rtve.es

http://www.elmundo.es

http://www.larazon.es

http://www.abc.es

http://www.laguiatv.com/actualidad/noticia/

http://es.news.yahoo.com

http://www.blogdeladversario.blogspot.com

http://www.elpais.com

http://www.heraldo.es

http://www.diariosigloxxi.com

http://www.libertaddigital.com

http://www.diariocritico.com

http://www.elsemanaldigital.com

http://www.vertele.com

Las consultas fueron hechas los días 30 de marzo y 24 de abril de 2007. 